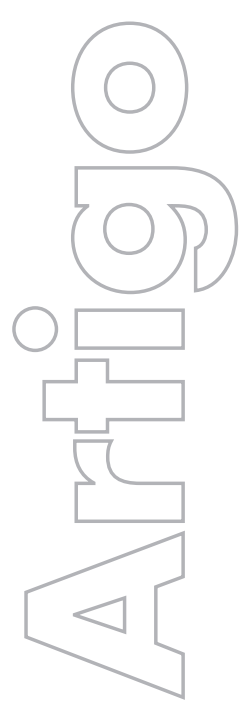

\section{revista}

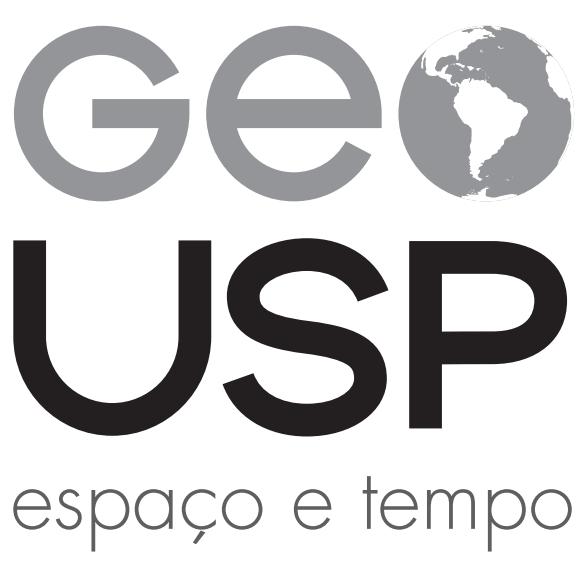

Volume $23 \cdot n^{\circ} 2$ (2019)

\section{Transporte fluvial no Solimões: uma leitura a} partir das lanchas Ajato no Amazonas

\section{Kristian Oliveira de Queiroz}

Universidade do Estado do Amazonas - Brasil

p. $322-341$

Como citar este artigo:

QUEIROZ, K. O. Transporte fluvial no Solimões: uma leitura a partir das lanchas Ajato no Amazonas. Geousp Espaço e Tempo (Online), v. 23, n. 2, p. 322-341, ago. 2019. ISSN 2179-0892.

Disponível em: https://www.revistas.usp.br/geousp/article/ view/133370. doi: https://doi.org/10.11606/issn.2179-0892. geousp.2019.133370.

\section{(C) $(1)(9$}

Este artigo está licenciado sob a Creative Commons Attribution 4.0 License. 


\title{
Transporte fluvial no Solimões: uma leitura a partir das lanchas Ajato no Amazonas
}

\section{Resumo}

As lanchas do transporte fluvial de passageiros da empresa Ajato no estado do Amazonas são as embarcações desse segmento mais atuantes na circulação regional do rio Solimões. Este artigo discute o transporte fluvial de passageiros no Solimões a partir de uma leitura do papel das lanchas Ajato na modernização do setor e mostra sua contribuição para a integração territorial nesse subespaço. Verificou-se que o transporte de passageiros no Solimões enfrenta dificuldades e desafios institucionais, infraestruturais e administrativos. No entanto, isso não impede a manutenção de fluxos significativos de embarcações diversas. As lanchas Ajato representam objetos úteis à circulação produzidos a partir de uma especialização do lugar; promovendo uma modernização da frota e uma integração territorial significativa nessa porção da formação socioespacial brasileira.

Palavras-chave: Transporte fluvial. Rio Solimões. Integração territorial. Modernização. Amazonas.

\section{River transport in Solimões: a reading by means of the Ajato Speedboats in the Amazonas}

\begin{abstract}
The speedboats of the river transport of passengers of the company Ajato in the state of Amazonas are the boats of this segment more active in the regional circulation of the river Solimões. This paper aims to discuss the river transport of passengers in the river Solimões from a reading of the role that the Speedboats Ajato carry out in the modernization of this sector, as well as to know its contribution to the territorial integration in this subspace. It was found that the transport of passengers in the Solimões River has difficulties and faces institutional, infrastructural and administrative challenges. However, this does not prevent the maintenance of significant flows of various vessels. The Ajato
\end{abstract}


speedboats are objects useful to the circulation produced from a specialization of the place; promoting a modernization of the fleet and a relevant territorial integration in this fraction of Brazilian social and spatial formation.

Keywords: River transport. Solimões River. Territorial integration. Modernization. Amazonas.

\section{Transporte fluvial en Solimões: una lectura por medio de las lanchas Ajato en el Amazonas}

\section{Resumen}

Las lanchas del transporte fluvial de pasajeros de la empresa Ajato en el estado de Amazonas son las embarcaciones de este segmento más activos en la circulación regional del río Solimões. Este artículo pretende discutir el transportefluvial de pasajeros en el río Solimões a partir de una lectura del papel que estos barcos rápidos de Ajato desempeñan en la modernización de este sector, así como conocer su contribución a la integración territorial en este subespacio. Se encontró que el transporte de pasajeros en el río Solimões tiene dificultades y enfrenta desafíos institucionales, infraestructurales y administrativos. Sin embargo, esto no impide el mantenimiento de flujos significativos de diferentes tipos de embarcaciones. Las lanchas Ajato son representantes de objetos útiles para la circulación producidos por una especialización del lugar; promoviendo una modernización de la flota y una integración territorial significativa en esta fracción de la formación socioespacial brasileña.

Palabras clave: Transporte fluvial. Río Solimões. Integración territorial. Modernización. Amazonas.

\section{Introdução}

O principal acesso às cidades do interior do Amazonas são as vias navegáveis de sua rede fluvial ou dentrítica. A geografia física constituída por rios, igarapés, paranás e furos permite a circulação nessa fração da formação socioespacial brasileira e a presença do modo de produção capitalista contemporâneo, ou a globalização.

Desde os tempos da expedição de Pedro Teixeira no século XVII até o período do regatão com barcos movidos a remo e a vela no século XIX, a navegação no rio Solimões no estado do Amazonas se realiza com o respeito aos limites impostos pela maior bacia hidrográfica do mundo, a bacia do rio Amazonas. Nesse momento, em 1855, os vapores da Companhia de Navegação e Comércio do Amazonas, pertencente ao Barão de Mauá, fazia regularmente a liga- 
ção entre o rio Negro e o Nauta, no Peru, levando 18 dias para cumprir o percurso de $1.800 \mathrm{~km}$ na subida do rio (Bates, 1979[1876], p. 204). Essa empresa de Mauá, que "incorporava quem the fizesse concorrência" (Nogueira, R., 1994), constituiu a The Amazon Steam Navigation, que capilarizou as atividades de navegação na Amazônia brasileira, peruana e boliviana, estrutura que permitiu a Manaus ligar-se diretamente a Gênova, Liverpool e Nova York, a partir da dinâmica da exploração da borracha amazônica (Nogueira, R., 1999, p. 77).

Atualmente, os barcos tradicionais da Amazônia operam com fluxos relevantes, mas apesar de sua alta capacidade de carga e passageiros ainda não atendem às normas e exigências da unicidade da técnica e do imperativo da rapidez dos dias atuais da globalização, pois são lentos e detentores de técnicas antigas. Nesse sentido, a rapidez e o aprimoramento das técnicas na navegação regional vêm sendo orientadas pela atuação das lanchas de transporte fluvial no Amazonas conhecidas como "expressos" ou Ajato (Figura 1).

Essas embarcações versáteis e potentes são resultado de uma modernização dos objetos da circulação regional amazônida. Concorrem com os outros tipos de embarcação do transporte regional de passageiros como os navios-motores (N/M) e os ferry-boats (F/B), chegando a influenciar a demanda da circulação pertinente ao transporte aéreo. Acabam por atender as necessidades do cotidiano e a expansão de novas técnicas provenientes de uma divisão territorial do trabalho inerente a espaços luminosos. Isto proporciona uma dialética do território, "o confronto dialogado entre o velho e novo, o local e o global, as verticalidades e as horizontalidades" (Silveira, M. L., 1999, p. 400).

\section{Figura 1 - As lanchas Ajato do rio Solimões}

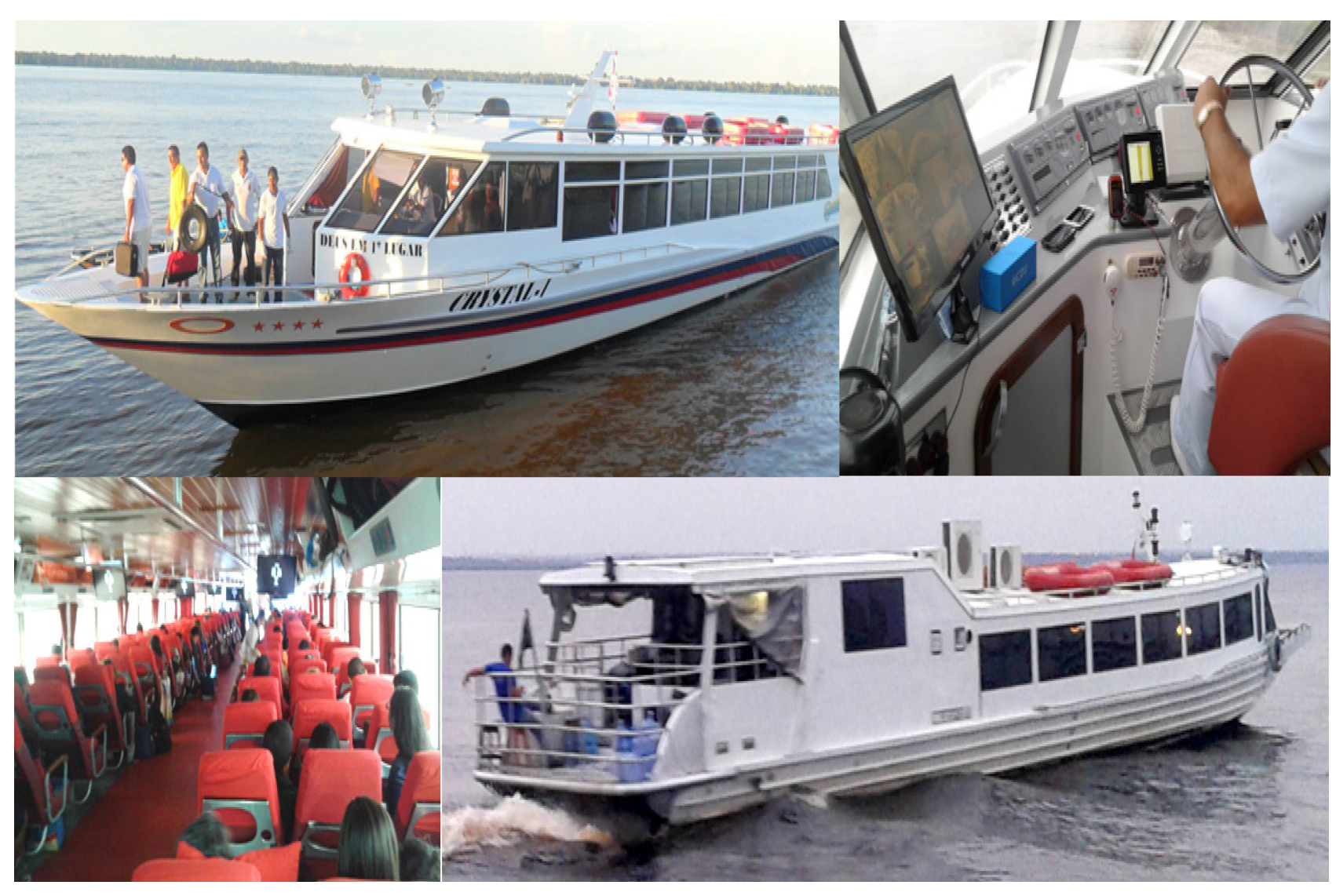

fonte: Acervo do autor, 2017. 
Esta pesquisa tem como objetivo analisar a infraestrutura e a dinâmica do transporte fluvial de passageiros no Solimões a partir do papel que as lanchas Ajato efetuam na modernização deste segmento da circulação regional e na integração territorial deste subespaço amazônida (Figura 2).

\section{Figura 2 - Área de estudo: o rio Solimões}

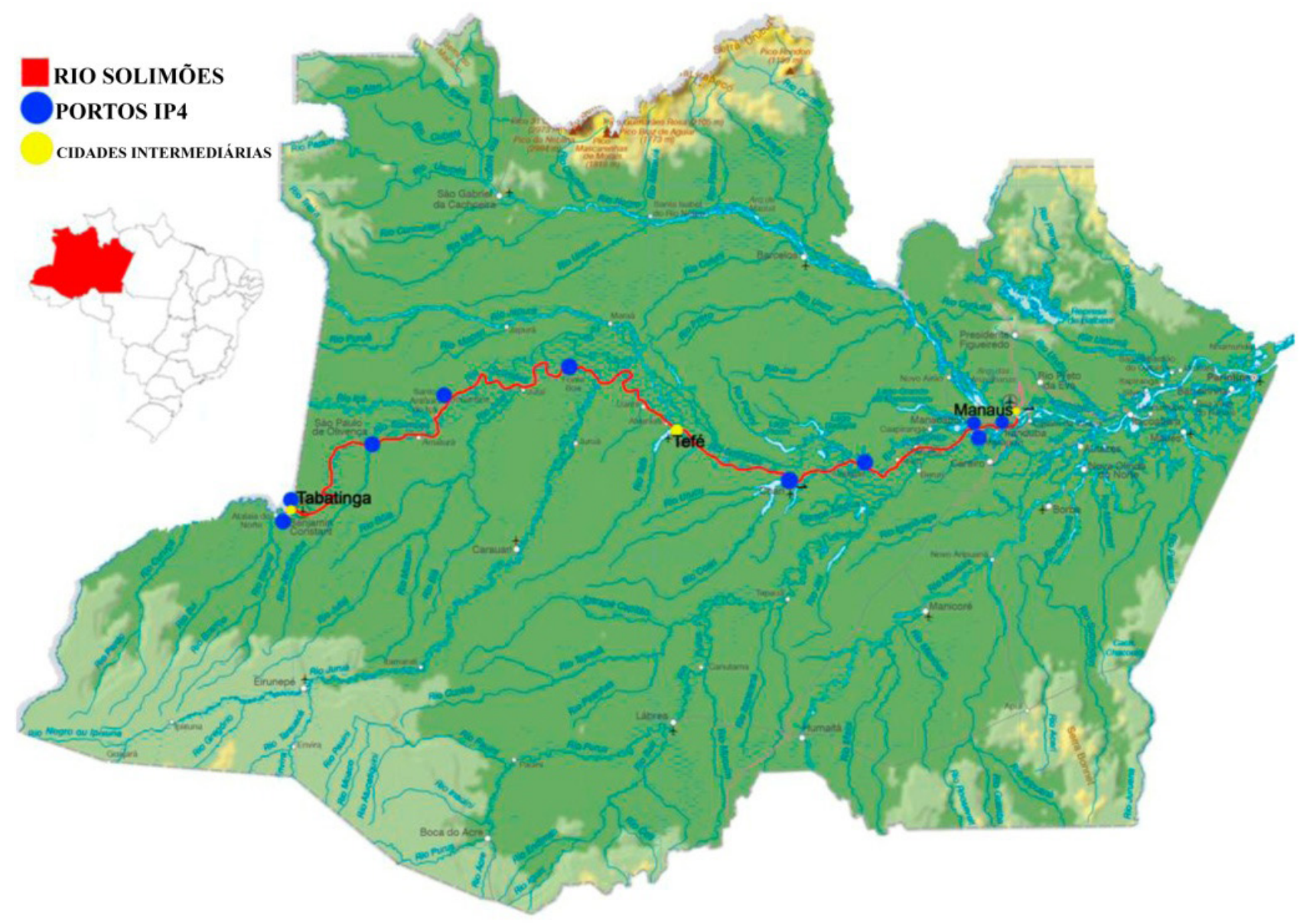

fonte: IBGE (2013). elaboração: $O$ autor.

Orientou esta pesquisa a hipótese de que as lanchas Ajato ensejaram uma modernização seletiva no percurso hidroviário do Solimões amazonense, com impacto no transporte fluvial regional, que influencia a dinâmica e a circulação econômica e social. A metodologia deste estudo adotou o levantamento bibliográfico e documental e o trabalho de campo realizado em toda a extensão do Solimões, dando prioridade à dinâmica dos fluxos das lanchas nos principais nodais desse percurso fluvial.

Este artigo fornece subsídios para compreender que as lanchas Ajato representam um produto de uma especialização do lugar, em razão de o Solimões exigir e impor condições de navegação por sua natureza particular. São 1.620 km de extensão sem balizamento ou sinalização, sem portos organizados e com baixa fiscalização, suscetíveis ao regime dos rios, com períodos de cheias e secas que exigem da tripulação experiência e leitura das condições físicas amazônidas. 


\section{A navegação no Solimões do Amazonas}

O Amazonas se configura como um "estado-floresta" (Queiroz, 2012). O maior estado brasileiro em extensão territorial tem grande parte de seu território "salvaguardada" por legislação nacional que, na Constituição Federal de 1988, delimita áreas protegidas, compostas pelas unidades de conservação e parques indígenas, no intuito de proteger e preservar seus recursos naturais e humanos.

Isto desenha um ordenamento territorial que propicia uma contenção territorial (Haesbaert, 2010) restringindo muitas vezes a circulação e o desenvolvimento a partir deste uso sustentável de suas potencialidades intrínsecas (Costa, 2008). Assim, numa região sem rodovias e ferrovias, é notória a importância dos rios, pois o transporte fluvial é fundamental para a circulação.

De acordo com dados da Agência Nacional de Transportes Aquaviários (Antaq) em pesquisa realizada em parceria com a Secretaria dos Portos (SEP), o transporte fluvial no estado do Amazonas tem 198 embarcações, com média de idade de 11 anos, circulando em 64 linhas de navegação (Antaq, 2013, p. 90). O Sindicato de Empresas de Navegação Fluvial do Estado do Amazonas (Sindarma, [s.d.]) afirma que aproximadamente 1,5 milhão de pessoas circulam em 85\% das principais rotas fluviais do estado (Antaq, 2013).

Em pesquisa realizada em 1978 em uma frota amazonense de 449 embarcações apenas 2 eram construídas de aço e o restante de madeira (Balau et al., 1978, p. 11). No ano de 2013, 15,7\% das respectivas 198 embarcações eram de aço e 61,6\% de madeira, além de 13,6\% de alumínio, 9,1\% de fibra (Antaq, 2013, p. 92). A Antaq afirma que o trabalho de cálculo da frota na região é complexo, poucas instituições prezam em fazê-lo pela dificuldade de cadastramento de empresas e armadores ${ }^{1}$ que estão em atividade. ${ }^{2}$

Entre os principais tipos de embarcação que navegam no Solimões, encontram-se: (i) o N/M, embarcação tradicional também conhecida como "recreio", cuja principal característica é o transporte misto de passageiros e carga, (ii) as lanchas de passageiros conhecidas como "expressos", Ajato ou lancha-motor (L/M) são um segmento do transporte fluvial muito difundido pela rapidez nas grandes distâncias amazônicas e dão prioridade ao transporte de passageiros, embora levem volumes limitados de carga por um custo mais alto que suas concorrentes, (iii) o F/B é um tipo de embarcação nos rios amazônidas que se compara em desempenho a um $\mathrm{N} / \mathrm{M}$, mas tem estrutura e forma diferentes, com o calado menor, como o de uma balsa, e também não permite que os passageiros usem redes, apenas camarotes, (iv) empurradas por um barco "rebocador", as balsas levam veículos maiores, assim como mercadorias como seixo, material de construção, combustível, madeira etc., (v) os navios cargueiros operam no Solimões a partir do terminal de uso privativo (TUP) de Coari levando a produção de hidrocarbonetos da Província Petrolífera de Urucu. Há cargueiros "roro caboclo", expressão derivada do inglês roll on roll off que, abreviada, gera o "rô-rô" (Ferreira, 2016); trata-se de um navio com capacidade para transportar veículos que circulam com ou sem contêineres de dentro da embarcação para

\footnotetext{
1 Armador é a pessoa física ou jurídica que equipa, mantém e explora comercialmente a embarcação mercantil, podendo ser ou não seu proprietário (CNT, 2013, p. 272).

2 Entrevista concedida pelo sr. Wilson Teodoro, técnico de regulação da Antaq, em Manaus, em 28 de dezembro de 2016.
} 
as estruturas do porto, e, finalmente, (vi) as pequenas catraias que ainda são importantíssimas para a comunicação e integração das comunidades mais isoladas e carentes tanto do Solimões como de seus diversos afluentes e sub-afluentes; são canoas com motores de popa tipo rabeta, levam grande parte da produção agrícola de subsistência dos caboclos, base da economia do interior do Amazonas (Figura 3). Os botes de alumínio com motor de popa são as "voadeiras".

\section{Figura 3 - Principais embarcações do rio Solimões}

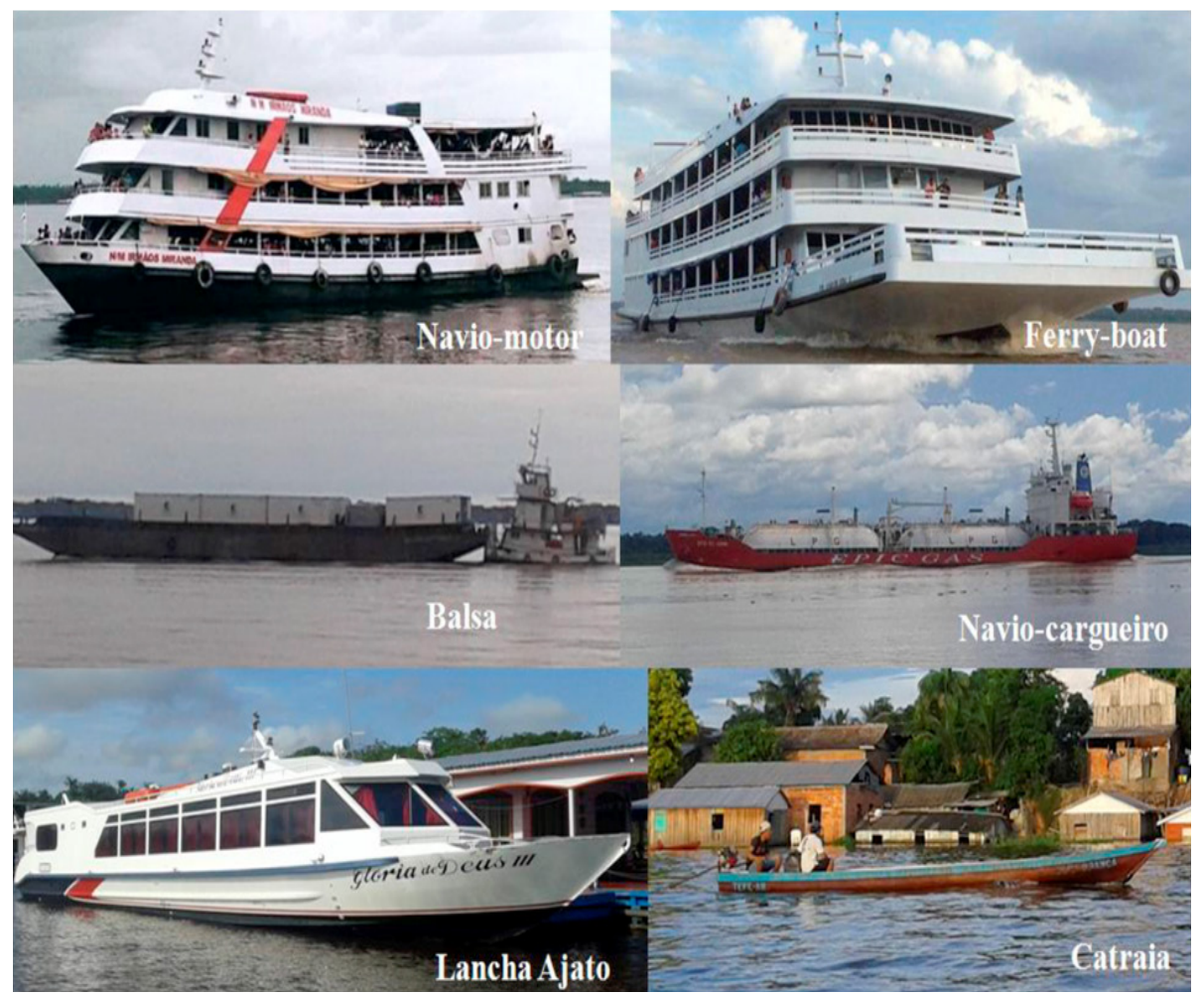

fonte: Acervo do autor, 2016.

Porto de Manaus no Amazonas é o maior porto organizado 3 flutuante do mundo e um dos mais importantes do país em razão das atividades vinculadas às 600 indústrias do Polo Industrial de Manaus (PIM). Entretanto, o estado do Amazonas tem apenas 30 terminais de passageiros distribuídos nos 62 municípios e não há um porto organizado em nenhum dos municípios do Solimões. Existem apenas "instalações rudimentares" (flutuantes de madeira, balsas-porto e terminais privados como os do Ajato) e os chamados IP4 nome de uma instalação portuária pública de pequeno porte, instaladas em dez dos 21 municípios situados às margens do Solimões. ${ }^{4}$ Esses portos são administrados pelo Departamento Nacional de Infraestruturas de Transportes (Dnit). O TUP de Coari pertencente à Petrobras é o único do Solimões.

3 Porto Organizadoéo "bem público construído e aparelhado para atender às necessidades de navegação, de movimentação de passageiros ou de movimentação e armazenagem de mercadorias, e cujo tráfego e operações portuárias estejam sob jurisdição de autoridade portuária" (Antaq, 2015, p. 280).

4 Os municípios às margens do Solimões são: Alvarães, Amaturá, Anori, Anamã, Benjamin Constant, Beruri, Caapiranga, Careiro da Várzea, Coari, Codajás, Fonte Boa, Iranduba, Jutaí, Manacapuru, Manaquiri, Santo Antônio do Içá, São Paulo de Olivença, Tefé, Tonantins, Uarini e Tabatinga. As cidades de Manaquiri e Caapiranga não ficam nas margens do Solimões, mas só são acessíveis fluvialmente pelo grande rio. A capital Manaus está no rio Negro, perto da confluência com o Solimões; desse encontro se origina o rio Amazonas e, nessa capital, os fluxos mais importantes para o Solimões. 
A Administração Hidroviária da Amazônia Ocidental (Ahimoc) $)^{5}$ providencia as demandas acolhidas pelo Dnit nos portos das cidades do Solimões que têm IP4. Em sua jurisdição geográfica, compete a essa administração "desenvolver atividades de execução e acompanhamento de estudos, obras, serviços e exploração das vias navegáveis interiores, bem como dos portos fluviais e lacustres que the sejam atribuídos pelo Dnit" (CNT, 2013, p. 37). Nos municípios que têm portos IP4, há licitações para que empresas terceirizem a administração, os serviços de vigilância e a manutenção da operacionalidade (Figura 4).

Figura 4 - Instalações portuárias públicas de pequeno porte (IP4) de Coari, Codajás e Tonantins (à esquerda) e as instalações portuárias rudimentares de Tefé, Tabatinga e Jutaí (à direita)

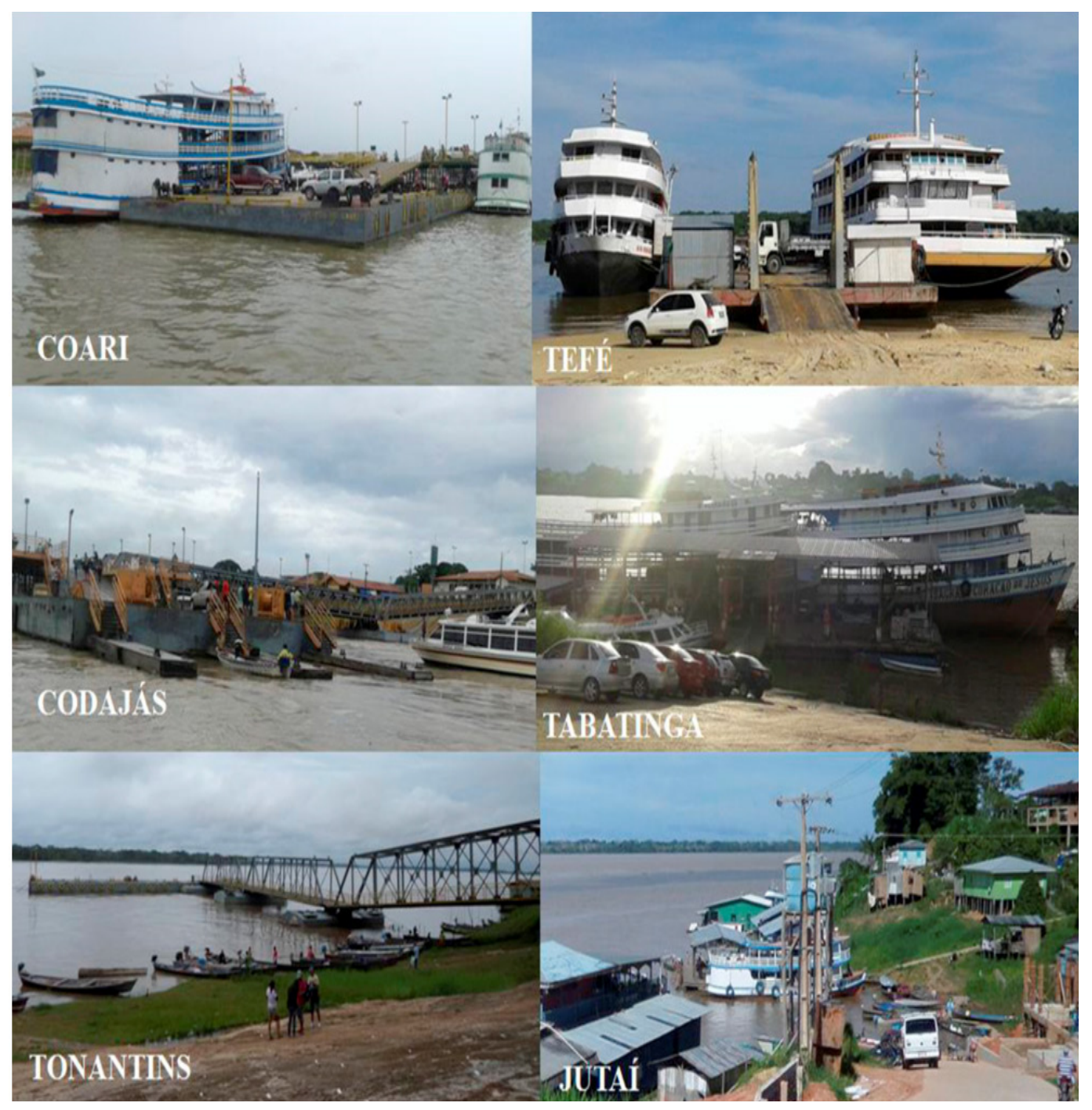

fonte: Acervo do autor, 2016.

5 A malha hidrográfica brasileira é regida por administrações hidroviárias subordinadas gerencialmente às Companhias Docas e ao Departamento de Infraestrutura Aquaviária do DNIT. "Atualmente existem oito administrações hidroviárias do Brasil: Administração Hidroviária do Paraguai (Ahipar); Administração Hidroviária do Tocantins-Araguaia (Ahitar); Administração Hidroviária da Amazônia Ocidental (Ahimoc); Administração Hidroviária da Amazônia Oriental (Ahimor); Administração Hidroviária do São Francisco (Ahsfra); Administração Hidroviária do Nordeste (Ahinor); Administração Hidroviária do Sul (Ahsul); e Administração Hidroviária do Paraná (Ahrana)" (CNT, 2013, p. 37). 
Os municípios do Solimões que têm instalações IP4 são: Benjamin Constant, Coari, Codajás, Fonte Boa, Iranduba, Manacapuru, Manaquiri, São Paulo de Olivença, Tabatinga e Tonantins. Chamados de "terminais hidroviários" nesses municípios, às vezes não estão disponíveis para as embarcações, devido a problemas administrativos ou institucionais, como é o caso de Tabatinga e foi o de Tonantins, suscetíveis a ficar "temporariamente" inoperantes.

Nessa situação, os fixos especializados no transporte fluvial regional continuam a ser os tradicionais e antigos flutuantes usados pelas embarcações de cargas e passageiros, as chamadas "instalações rudimentares".

Ressalta-se o papel dos postos flutuantes, conhecidos como "pontões", presentes nas principais cidades como Tefé, Coari e Tabatinga; fornecem abastecimento de combustíveis para as embarcações auxiliando nas longas viagens pelo "rio mar".

transporte de passageiros no Amazonas do Solimões enfrenta dificuldades e desafios institucionais, infraestruturais e administrativos, assim como em toda a Amazônia. A Antaq (2013) discute assim as características e dificuldades do transporte de passageiros na região amazônica:

A maioria das linhas da Amazônia ainda são servidas por embarcações de tecnologias ultrapassadas e em muitos casos construídas em madeira ou em aço com idades superiores a dezenas de anos; no entanto, observa-se regularmente, que após reformas e adequações, as mesmas geralmente obtêm nova idade. Sem ação do Estado por intermédio de subsídios e subvenções é impossível qualquer empresário suportar os investimentos em tecnologias mais modernas entre centros populacionais de baixa aglomeração e baixa renda. [...] As embarcações que realizam o transporte fluvial de passageiros na Amazônia, de forma recorrente, apresentam problemas de conforto, higiene e segurança. [...] A baixa qualidade dos serviços, do conforto e segurança são justificadas pela necessidade de cobrar tarifas de baixo valor [...]. Sua população, na grande maioria, apresenta padrão de renda e nível de vida bastante baixos. Seu comércio é ainda incipiente e pouco dinâmico; entretanto, o transporte fluvial através de embarcações mistas (passageiros e cargas) continua sendo a base de todo o comércio ao longo da calha principal do rio Amazonas e seus afluentes. Como o transporte fluvial é praticamente o único meio de locomoção de baixo custo na região, as embarcações hoje existentes desempenham um papel social relevante para as inúmeras localidades ribeirinhas servidas por elas. [...] Os terminais ainda são inadequados e não possuem, em sua grande maioria, os equipamentos necessários para a operação do transporte com passageiros (Antaq, 2013, p. 99).

A Confederação Nacional de Transportes (CNT) constatou que, entre as grandes preocupações dos armadores da região Norte, particularmente do Amazonas, destacam-se "os roubos de cargas, a ineficiência nos portos e a carência de terminais" (CNT, 2013, p. 151). Para Pereira (2014, p. 140), nunca houve no Brasil uma política nacional de transportes, mas apenas, por mais de 30 anos, investimentos restritos, abaixo de 2\% do PIB nacional: "navegação interior teve importância econômica discreta e foi incapaz de gerar núcleos de desenvolvimento, em grande parte pelo total descaso sobre o assunto, tanto do governo federal e estaduais quanto do setor privado" (Pereira, 2014, p. 73-74). 
Apesar de tantos empecilhos relativos às condições sociais e econômicas da população e à geografia física da Bacia Amazônica, a maior do mundo, o transporte fluvial de passageiros no Solimões, rota Manaus-Tabatinga, tem o maior índice de "satisfação positiva" na Amazônia, com nota 7,5 (CNT, 2013).

Isto permite que fluxos sejam estabelecidos de maneira a manter e valorizar os armadores e suas respectivas rotas que compõem a navegação de passageiros nesta extensa parcela da formação socioespacial brasileira (Quadro 1).

\section{Quadro 1 - Embarcações que fazem regularmente a rota Manaus-Taba- tinga, ou seja, toda a extensão do rio Solimões - janeiro de 2017}

\begin{tabular}{|l|l|l|}
\hline navio-motor (N/M) & lancha-motor (L/M) & ferry-boat (F/B) \\
\hline N/M GM Oliveira & L/M Crystal I & F/B Fenix II \\
\hline N/M Voyager III & L/M Madame Crys & F/B M. Monteiro II \\
\hline N/M Itapuranga & L/M Glória de Deus III & F/B Diamante \\
\hline N/M M. Monteiro & L/M Cidade de Manaquiri & \\
\hline N/M O Rei Davi & & \\
\hline N/M Voyager IV & & \\
\hline N/M M. Fernandes & & \\
\hline $\begin{array}{l}\text { N/M Sagrado Coração de } \\
\text { Jesus }\end{array}$ & & \\
\hline N/M Itaberaba I & & \\
\hline
\end{tabular}

fonte: Elaboração própria, 2017.

Esses fluxos valorizados pela demanda relevante atraem investimentos daqueles que buscam aumentar a eficiência em razão do lucro, acabam por modernizar as rotas e, consequentemente, os fluxos. No entanto, um processo de modernização e intensificação dos fluxos numa via fluvial com a extensão do Solimões requer esforço governamental e empenho dos investidores e armadores do transporte fluvial no Solimões, submetidos à burocracia e às limitações físicas impostas pela natureza amazônica.

\section{O Solimões e o impacto da especialização do lugar na navegação}

De acordo com a CNT (2013, p. 278), uma hidrovia é "uma via navegável devidamente melhorada para o transporte fluvial em larga escala e empresarialmente viável". É necessário que existam portos estruturados, balizamento, sinalização e fiscalização para que uma hidrovia funcione. Todavia, apesar de ser considerado uma hidrovia, o Solimões não atende a essas especificações e é reconhecido por muitos técnicos fluviais e armadores como uma "via navegável", e não uma hidrovia efetiva. ${ }^{6}$ Entretanto, por suas características naturais, o rio oferece navegabilidade.

6 Entrevista concedida pelo sr. William Aquino, geógrafo e funcionário do Terminal Hidroviário de Tabatinga, em

Tabatinga, em 29 de outubro de 2016. 
Solimões é uma fração do maior rio do mundo em volume d'água; esse é o nome do segundo trecho do rio Amazonas, após o Marañon peruano. Em toda a sua extensão inserida em território amazonense, o Solimões tem aproximadamente 1.620 km de extensão navegável, com largura de até $20 \mathrm{~km}$ em alguns trechos no período da cheia (Brasil, [s.d.]); sua profundidade varia de 8 a 20 m na estação da cheia do rio e de 3 a 10 m na estação seca; não tem balizamento na maior parte de seu curso, e suas cartas náuticas são limitadas (Machado, 2014, p. 42). Seus contornos e caminhos mudam periodicamente, devido ao fato de ser um rio com leito geologicamente recente. Essas características exigem especialização da navegação, e as embarcações dependem da habilidade e da experiência da tripulação (Nogueira, A., 1995), que deve conhecer os atalhos e os segredos do percurso.

Entre os diversos riscos para a navegação, arrolamos: (i) os bancos de areia submersos e suas praias, (ii) o fenômeno das terras caídas que desmorona os barrancos de suas margens formando ondas, "banzeiros", que chegam a afundar balsas de transporte de veículos, (iii) o "rebojo", redemoinhos formados na confluência de velocidades distintas de suas águas que podem atrasar as viagens e mesmo afundar pequenos barcos, (iv) os diversos caminhos que se apresentam à frente das embarcações devido à formação de inúmeras ilhas (paranás) ao longo de sua extensão configurando verdadeiros labirintos para os que não conhecem suas entradas principais, (v) os materiais despojados naturalmente na superfície de suas águas como troncos de árvores que frequentemente quebram as hélices das embarcações, (vi) os perigos gerados pela atividade ilegal humana como os piratas dos rios, conhecidos como "ratos d'água", que são mais frequentes nas proximidades da tríplice fronteira em Tabatinga, sequestram e matam pessoas para roubar mercadorias e (vii) soma-se ao cenário do Alto Solimões a presença do narcotráfico, cujas ações ilegais aumentam a instabilidade da região por meio de uma significativa "porosidade territorial" (Arroyo; Cruz, 2015).

Assim, a navegação no Solimões se condiciona a operacionalidades que superem as dificuldades impostas pela natureza do rio. A circulação fluvial nesse subespaço obedece à configuração territorial particular e desenvolve-se a partir de uma especialização imposta pelo lugar. Sendo assim, a expansão dos transportes e das comunicações se realiza em uma divisão territorial do trabalho que admite técnicas tradicionais regionalmente adaptadas para que seus intercâmbios sejam estabelecidos.

De modo geral, há uma baixa densidade demográfica, técnica e informacional na região do Solimões, excetuando o entorno da capital, Manaus, situada no rio Negro, de onde partem e para onde se dirigem os grandes fluxos do Solimões. Costa (2008, p. 243) afirma que a dispersão de fluxos e a fragmentação do território são suscetíveis a uma aceleração da especialização das regiões, das sub-regiões e dos lugares, mais claramente observável em áreas metropolitanas como a de Manaus.

Segundo Márcio Rogério Silveira (2006, p. 104), não é simples identificar a especialização que podem oferecer determinados espaços: "a capacitação pode ser incentivada e aperfeiçoada, mas é improvável que seja simplesmente criada, especificamente, em áreas deprimidas, propensas a baixa cooperação e competição". 
Essa reflexão pode ser interpretada também a partir do transporte fluvial na Amazônia, em função da especialização de objetos próprios da navegação em bacias que contam com rios gigantescos, sinuosos e meândricos e por isso propensa a baixa competitividade em função da necessidade de altos investimentos em embarcações que possam cooperar para a exploração das respectivas potencialidades e recursos locais. Mais do que objetos próprios especializados nas viagens que possam eventualmente mitigar os empecilhos do percurso, a fluidez e segurança pertinente ao meio de transporte fluvial, primordial nesses espaços amazônicos, se ancora na especialização dos homens que dirigem os barcos, com sua experiência particular (Nogueira, A., 1995), e no aprimoramento dessas embarcações da navegação amazônida.

Nesse sentido, as lanchas de transporte fluvial no Solimões, os chamados Ajato ou expressos, representam um produto da especialização do lugar e uma modernização do transporte fluvial via a adaptação às condições de navegabilidade, pois obedecem aos imperativos físicos e naturais que oferecem resistências à circulação.

Entre os vetores das lanchas Ajato que a caracterizam como produto de uma especialização que permite uma melhor navegação no Solimões destaca-se: (i) a alta potência dos motores, que diminuem a duração das viagens nas longas distâncias entre as cidades, maiores que a de outros segmentos de transporte fluvial, (ii) o pequeno calado que possibilita menor arrasto na superfície, melhorando o desempenho também frente a profundidade variável do rio, principalmente nos períodos de seca, (iii) a melhor manobrabilidade permitindo desviar rapidamente de troncos de árvores e detritos flutuantes na superfície, (iv) o melhor equipamento de comunicação, a radiofonia aprimorada em caso de perigos diversos (incidentes, pirataria, naufrágios etc.), (v) aos modernos equipamentos de iluminação representados por potentes holofotes que mitigam a falta de balizadores da hidrovia na escuridão das viagens noturnas, (vi) os equipamentos de GPS para localização via satélite e ecobatímetro para gerenciamento da profundidade do rio, assim como do sistema de monitoramento dos motores e da tripulação como o uso de câmeras e pronto-socorro, e (vi) a presença de profissionais especializados nessa navegação amazônida, como técnicos e enfermeiros.

Assim, essas embarcações se configuram como produtos da modernização do transporte fluvial que atendem aos objetivos da circulação amazônida, comuns em lugares do mundo que se ajustam para sanar a demanda e o consumo da circulação, como os bateau-mouche, especializados no rio Sena, em Paris, e os barcos de transporte urbano especializados nos canais de Amsterdã, na Holanda.

A especialização do lugar, proveniente da adequação dos homens e seus objetos às condições de navegabilidade, teve impacto no transporte fluvial no rio Solimões. As lanchas Ajato são barcos aperfeiçoados para essa circulação regional na Bacia Amazônica. Frente às técnicas utilizadas pelos segmentos concorrentes do transporte fluvial na região, ainda lentos e pouco versáteis, estas lanchas atuam como um instrumento de modernização do transporte fluvial nesta região periférica. 
Santos (2008[1979], p. 32) toma o conceito de Wilbert E. Moore (1965) para acatar a modernização de um espaço como sua união econômica, política e social ao mundo moderno. Porém, nestes dias de globalização, há que refletir sobre o acesso redes, tecnologias e informações que permitem modernizações em espaços opacos como o Solimões, direcionando uma integração territorial parcial, limitada e relativa (Queiroz, 2015), pois muitas técnicas que deveriam suprir o funcionamento das novas formas e objetos espaciais não fazem parte da configuração territorial disponível.

Damiani (2006, p. 137) afirma que o "processo modernizador não se realiza da mesma forma em todos os lugares". Santos (2008[1979], p. 25) fala em "modernizações" e em "transformações sucessivas da organização do espaço". Para María Laura Silveira (1999, p. 434), muitos conhecem mais a palavra "modernização" do que seu significado. A geógrafa afirma que "o processo de modernização significa, entre outras coisas, uma cristalização do capital em técnicas novas" (Silveira, M. L., 1999, p. 328); enfatiza que "o processo pelo qual um território incorpora dados centrais do período histórico vigente que importam em transformações nos objetos, nas ações, enfim no modo de produção" chama-se modernização (Silveira, M. L., 1999, p. 22).

Evidencia-se que as lanchas em questão configuram-se como objetos modernos nos rios amazônicos, região detentora de uma modernização incompleta (Santos, 1994) e de fluxos hidroviários de frequência significativa. Na falta de estradas e rodovias, os rios da maior bacia hidrográfica do mundo permitem a circulação de pessoas, mercadorias, ideias e capitais. Ressalta-se que o Solimões só é integralmente navegável de Manaus a Coari, a montante; daí a Tabatinga, os fluxos fluviais devem atender às "peculiaridades" do rio, ao contrário do Amazonas, que é integralmente navegável de Manaus a Belém, a jusante (Machado, 2014).

A especialização do lugar providencia a especialização dos fluxos, logo, a modernização dos lugares pode ser concomitante à modernização desses fluxos. Concordamos com Huertas (2007, p. 251) quando afirma que a consequência das inovações tecnológicas mais influentes na navegação regional amazônida é o aumento da velocidade, que leva à gradativa troca de embarcações de madeira por embarcações de ferro ou aço. Em sua análise do transporte fluvial na Amazônia, Rogério Nogueira (1999, p. 78) afirma que o setor de transporte está continuamente submetido a inovações tecnológicas voltadas para o aumento da capacidade de carga e a redução do custo de produção com o respectivo aumento da velocidade. Nesse sentido, as lanchas Ajato respondem a esse argumento permitindo a redução do espaço pelo tempo em função da potência dos motores e da incorporação de técnicas de operação mais modernas que os segmentos da navegação regional.

Uma modernização territorial que se realize em sintonia com os condicionantes naturais de uma região como relevo, hidrografia, clima e vegetação e sua respectiva divisão territorial do trabalho, muitas vezes foge ao padrão do processo modernizador hegemônico, que usa técnicas contemporâneas para contemplar as necessidades da circulação e da dinamicidade dos fluxos.

"O moderno nem sempre é o novo" (Santos, 1999). Muitas vezes, a modernização se 
realiza por meio de técnicas envelhecidas de diferentes temporalidades que são utilizadas devido ao não provimento técnico do território, ou por um provimento de sistemas técnicos antigos e sobrepostos aos modernos. Nesse sentido, Cataia (2001) chama de "ortopedia territorial" a composição do território por sistemas técnicos que são produzidos e sobrepostos em camadas técnicas chamadas "próteses" que permitem a ação humana no território.

A modernização dos fluxos é consequência de uma produtividade espacial aprimorada, resultado da especialização do lugar e das novas necessidades impostas pelo avanço da técnica e da rapidez inerentes ao meio geográfico contemporâneo.

\section{As lanchas Ajato no Solimões: integração e modernização do território}

Na "Amazônia do Solimões", as densidades técnica e informacional do território são rarefeitas, seus fixos especializados na navegação são limitados. Logo, as embarcações que circulam nesse rio devem estar preparadas ou adaptadas para operar em suas águas, desprovidas de portos organizados e condicionadas à precária infraestrutura de seus terminais hidroviários e instalações rudimentares, majoritariamente feitos de madeira ou adaptados às balsas ou aos barrancos das margens do rio.

A Antaq tem afirmado que o desequilibrio socioeconômico implica diferenças entre os terminais no Amazonas e que os problemas operacionais dos terminais aumentam na mesma proporção das distâncias à capital, Manaus (Antaq, 2013, p. 36).

Assim, as embarcações precisam estar aptas a atracar, embarcar e desembarcar passageiros e cargas com eficiência e segurança não apenas em cidades ou portos do interior do Solimões, mas também nas comunidades e vilas existentes no percurso.

Nesse contexto, o processo de modernização dessas embarcações se realiza pela incorporação de estruturas, equipamentos e técnicas capazes de funcionar nos lugares amazônicos onde a assistência técnica é incipiente.

Nessas condições, as embarcações do segmento L/M navegam pelo Solimões e seus afluentes, aprimorando seus fluxos, dinamizando o mercado e produzindo competitividade em razão da diminuição da duração das viagens. A sua característica e a oferta primordial que conquista os clientes é a aceleração.

A empresa Ajato Navegações Ltda ME é pioneira no segmento L/M; tão notória, que elas levam seu nome, pela força do uso: chamam-se "lanchas Ajato". Centraliza a origem das rotas do Solimões na capital do estado, Manaus. "A familia Ajato", como é conhecida, tem empresas parceiras que operam no Terminal do Ajato de Manaus, localizado no Poligonal do Porto de Manaus, o Porto da Manaus Moderna. As lanchas Ajato que zarpam do terminal de Manaus pertencem às respectivas empresas ou armadores parceiros: (i) F. de A. O. dos Reis Ltda, de Manaus, (ii) Jecile M . Pinheiro Ltda, de Manaus, (iii) Ana Clara Navegação Ltda, da cidade de Borba, (iv) M. J. P Monteiro Ltda, de Manaus, (v) Lancha Crystal I. R. P. Monteiro Ltda, de Manaus, (vi) Lancha Pérola Ltda, de Manaus, (vii) Reis Monteiros Navegação Ltda, de Manaquiri, e (viii) Expresso Navegação, Comércio e Prestação de Serviços Ltda, de Itacoatiara $^{7}$ (Quadro 2).

7 Entrevista concedida pela sra. Luane Paes, assessora da empresa Ajato Navegações Ltda. ME, em Manaus, em 28 de 
Quadro 2 - Caracterização da empresa Ajato

\begin{tabular}{|c|c|c|c|c|c|c|c|c|}
\hline \multirow[b]{2}{*}{ lancha } & \multicolumn{2}{|c|}{ motor } & \multirow[b]{2}{*}{$\begin{array}{l}n^{\circ} \text { pas- } \\
\text { sageiros }\end{array}$} & \multirow{2}{*}{$\begin{array}{l}\text { rota e } \\
\text { distân- } \\
\text { cia de } \\
\text { Manaus }\end{array}$} & \multirow{2}{*}{$\begin{array}{l}\text { du- } \\
\text { ração } \\
\text { da } \\
\text { viagem }\end{array}$} & \multirow{2}{*}{$\begin{array}{l}\text { frequên- } \\
\text { cia (nº } \\
\text { saídas de } \\
\text { Manaus) }\end{array}$} & \multirow{2}{*}{$\begin{array}{l}\text { preço } \\
\text { da pas- } \\
\text { sagem } \\
(\text { em } R \$)\end{array}$} & \multirow[b]{2}{*}{$\begin{array}{l}\text { cidades percorridas na } \\
\text { rota }\end{array}$} \\
\hline & n. & $\mathrm{HP}$ & & & & & & \\
\hline $\begin{array}{l}\text { Ajato } \\
2000\end{array}$ & 1 & 600 & 72 & $\begin{array}{l}\text { Tefé } \\
(631 \mathrm{~km})\end{array}$ & $12 \mathrm{~h}$ & $\begin{array}{l}3 \text { (segundas, } \\
\text { quartas e } \\
\text { sábados) }\end{array}$ & 230,00 & Codajás, Coari, Tefé. \\
\hline $\begin{array}{l}\text { Glória de } \\
\text { Deus III }\end{array}$ & 2 & 500 & 95 & $\begin{array}{c}\text { Tabatinga } \\
(1.573 \mathrm{~km})\end{array}$ & $36 \mathrm{~h}$ & 1 (sextas) & 570,00 & $\begin{array}{l}\text { Codajás, Coari, Tefé, Al- } \\
\text { varães, Fonte Boa, Jutaí, } \\
\text { Tonantins, Santo Antônio do } \\
\text { Içá, Amaturá, São Paulo de } \\
\text { Olivença, Benjamin Cons- } \\
\text { tant, Tabatinga. }\end{array}$ \\
\hline $\begin{array}{l}\text { Madame } \\
\text { Crys }\end{array}$ & 2 & 600 & 130 & $\begin{array}{l}\text { Tabatinga } \\
(1.573 \mathrm{~km})\end{array}$ & $36 \mathrm{~h}$ & 1 (quintas) & 570,00 & $\begin{array}{l}\text { Codajás, Coari, Tefé, Al- } \\
\text { varães, Fonte Boa, Jutaí, } \\
\text { Tonantins, Santo Antônio do } \\
\text { Içá, Amaturá, São Paulo de } \\
\text { Olivença, Benjamin Cons- } \\
\text { tant, Tabatinga. }\end{array}$ \\
\hline Crystal I & 3 & 600 & 145 & $\begin{array}{l}\text { Tabatinga } \\
(1.573 \mathrm{~km})\end{array}$ & $36 \mathrm{~h}$ & 1 (terças) & 570,00 & $\begin{array}{l}\text { Codajás, Coari, Tefé, Al- } \\
\text { varães, Fonte Boa, Jutaí, } \\
\text { Tonantins, Santo Antônio do } \\
\text { Içá, Amaturá, São Paulo de } \\
\text { Olivença, Benjamin Cons- } \\
\text { tant, Tabatinga. }\end{array}$ \\
\hline Puma & 1 & 600 & 65 & $\begin{array}{l}\text { Tefé } \\
(631 \text { km) }\end{array}$ & $12 \mathrm{~h}$ & $\begin{array}{l}2 \text { (sextas e } \\
\text { domingos) }\end{array}$ & 230,00 & Codajás, Coari, Tefé. \\
\hline $\begin{array}{l}\text { Cidade de } \\
\text { Manaquiri }\end{array}$ & 2 & 500 & 95 & $\begin{array}{l}\text { Tabatinga } \\
(1.573 \mathrm{~km})\end{array}$ & $36 \mathrm{~h}$ & 1 (domingos) & 570,00 & $\begin{array}{l}\text { Codajás, Coari, Tefé, Al- } \\
\text { varães, Fonte Boa, Jutaí, } \\
\text { Tonantins, Santo Antônio do } \\
\text { Içá Amaturá, São Paulo de } \\
\text { Olivença, Benjamin Cons- } \\
\text { tant, Tabatinga. }\end{array}$ \\
\hline $\begin{array}{l}\text { Zé Ho- } \\
\text { landa }\end{array}$ & 2 & 600 & 105 & $\begin{array}{l}\text { Novo } \\
\text { Aripuanã } \\
(489 \mathrm{~km})\end{array}$ & $9 \mathrm{~h}$ & 1 (sextas) & 230,00 & $\begin{array}{l}\text { Borba, Nova Olinda do } \\
\text { Note, Novo Aripuanã. }\end{array}$ \\
\hline Missone & 2 & 650 & 120 & \begin{tabular}{|l|} 
Novo \\
Aripuanã \\
$(489 \mathrm{~km})$ \\
\end{tabular} & $9 \mathrm{~h}$ & 1 (terças) & 230,00 & $\begin{array}{l}\text { Borba, Nova Olinda do } \\
\text { Note, Novo Aripuanã. }\end{array}$ \\
\hline Pérola & 1 & 600 & 70 & $\begin{array}{l}\text { Novo } \\
\text { Aripuanã } \\
(489 \mathrm{~km})\end{array}$ & $9 \mathrm{~h}$ & $\begin{array}{l}2 \text { (segundas } \\
\text { e quintas) }\end{array}$ & 180,00 & $\begin{array}{l}\text { Borba, Nova Olinda do } \\
\text { Note, Novo Aripuanã. }\end{array}$ \\
\hline Belíssima & 1 & 600 & 90 & $\begin{array}{l}\text { Carauari } \\
(1.411 \mathrm{~km})\end{array}$ & $34 \mathrm{~h}$ & 1 (quartas) & 500,00 & $\begin{array}{l}\text { Codajás, Coari, Tefé, Alva- } \\
\text { rães, Juruá, Carauari. }\end{array}$ \\
\hline
\end{tabular}

fonte: Elaboração própria, com base nos dados da entrevista concedida pelo sr. Aguiar, proprietário da Ajato Navegações Ltda ME, em janeiro de 2017. 
Essas empresas parceiras trabalham sob a gestão do sr. Aguiar, proprietário da Ajato Ltda e o grande idealizador do design que batizou de "modelo manauara"; aliás, foi ele quem construiu as primeiras lanchas Ajato. Inicialmente, ele chamava de "barcos rápidos" essas embarcações alternativas de transporte de passageiros na Amazônia. Afirma que foi uma "proposta pessoal" de transporte fluvial para operar no entorno de Manaus em 1993. As linhas para o Solimões começaram em janeiro de 2000. Atualmente, uma lancha Ajato custa entre R\$ 800 mil e R 7 milhões. A lancha mais antiga da família Ajato conta 17 anos e a mais nova, dois meses. $^{8}$

O sr. Aguiar atua como consultor de empresas novas que estão construindo suas lanchas para ingressar no mercado da navegação amazônida, inclusive fazendo sugestões às estruturas dos F/B, que concorrem diretamente com os fluxos dos N/M no Amazonas. A empresa Ajato socializa com outras empresas parceiras do ramo as estruturas de seus terminais e de seus serviços como o terminal de passageiros em Manaus e Tefé (Figura 5).

\section{Figura 5 - Os terminais das lanchas Ajato, de Manaus (acima) e de Tefé (abaixo)}

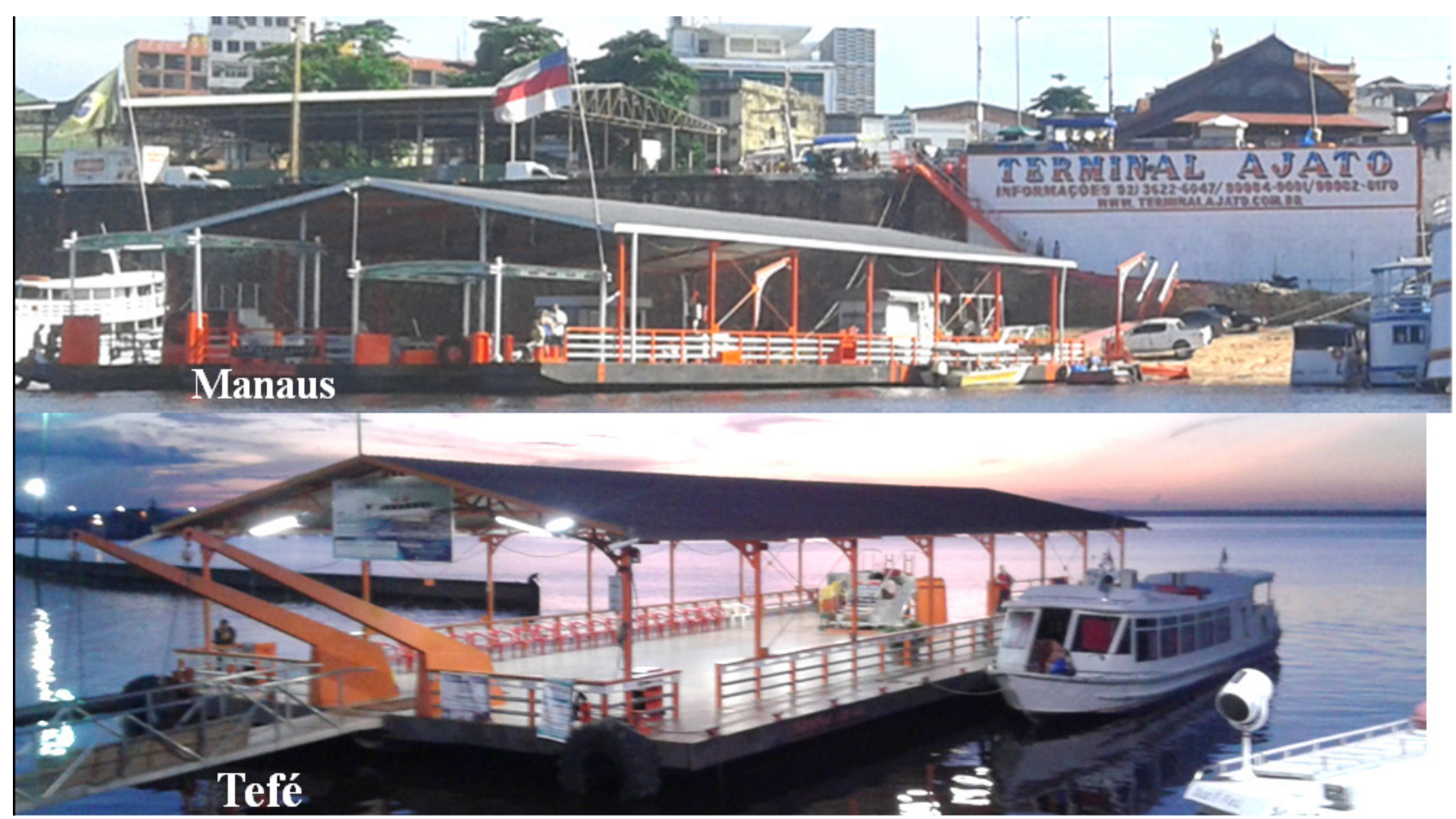

fonte: Acervo do autor, 2016.

Outros empresários/armadores buscam adentrar no mercado do Solimões a partir da estrutura estabelecida pela empresa Ajato. Exemplos são as lanchas Deus de Aliança III, da rota Manaus-Jutaí, em 2016; as lanchas Golfinho e Rio Belk são exemplos na rota Manaus- Tefé. No entanto, em função da concorrência e competitividade do setor nas rotas já estabelecidas, esses armadores não continuaram na família Ajato, como foi o caso da Deus de Aliança

8 Entrevista concedida pelo sr. Aguiar, proprietário da empresa Ajato Navegações Ltda. ME, em Manaus, em 28 de dezembro de 2016. 
III. No caso das outras duas, mesmo seguindo com a parceria da empresa Ajato, não foi possível se estabelecerem nas respectivas rotas no Solimões, alternando seus serviços com outras rotas, como Manaus-Santarém, atendendo à demanda das respectivas cidades a jusante do rio Amazonas.

Assim, constituíram-se redes em função dos nodais economicamente significativos no Solimões, e, nessas redes, o capital se apresenta com o inexorável interesse de intensificá-las.

Os atores principais do segmento L/M do transporte fluvial no Solimões que atuam junto à empresa Ajato usam como estratégia funcional as estruturas pertencentes ao sr. Aguiar, tais como os terminais de Manaus e de Tefé e a assistência técnica disponibilizada pela empresa Ajato a esses armadores. Estes, por sua vez, fazem suas viagens tanto pelo Solimões quanto por seus afluentes, rios secundários que compreendem cidades nos rios Juruá, Japurá e Purus.

Ressalta-se que, em função da limitação e escassez de terminais de embarque e desembarque de passageiros no Solimões, o terminal do Ajato em Tefé 9 dá uma expressão particular e distinta, por oferecer suporte a esses procedimentos de embarque e desembarque não apenas às lanchas Ajato, mas a outros barcos, catraias e voadeiras. Assim, objetos técnicos que atendem as lanchas Ajato acabam por aprimorar os fixos e, concomitantemente, os fluxos no Solimões a partir de suas operacionalidades.

Nesse contexto, os terminais de Tefé e de Manaus são produtos de uma modernização territorial dos fixos especializados na navegação regional por oferecer infraestruturas e serviços que não estão disponíveis em outros terminais regionais, principalmente em Tefé, maior centro urbano do Solimões. Infraestruturas e serviços como: gerador de energia; ${ }^{10}$ guichê de vendas de passagens; escada para embarque e desembarque de idosos e crianças; acesso facilitado no período de seca (praia) e de cheia dos rios. Além de utilizarem técnicas e organização diferenciadas (lanche, cadeiras, carregadores, taxistas etc.). Apesar disto, esses Terminais do Ajato são reconhecidos como uma Instalação Rudimentar pela Antaq.

Conhecidos como "pontões", os postos de combustível flutuantes são fixos especializados no abastecimento de embarcações de todos os tipos no Solimões, fundamentais para a navegação e presentes principalmente nos municípios de Tefé, Coari e Tabatinga. No entanto, nas águas dos municípios do Alto Solimões não há pontões, apenas flutuantes de madeira com equipamentos antigos e precários que improvisaram esse serviço de abastecimento. Uma L/M Ajato precisa, em média, de 200 litros de combustível por hora, ou seja, para que as viagens sejam rápidas, o abastecimento também deve ser rápido. No entanto, flutuantes e pequenos barcos de abastecimento que usam técnicas antigas e equipamentos pretéritos não viabilizam esse serviço de maneira ágil. Tripulações das lanchas Ajato afirmam que, mesmo com o combustível mais caro, esses flutuantes que dispõem de diesel e gasolina "muitas vezes são alternativas valiosas" "ll para prosseguir uma viagem.

9 O município de Tefé é considerado nó de rede e gestor do território nesse subespaço em virtude de sua posição estratégica, que lhe proporciona fixos e fluxos significativos na região (Queiroz, 2015). No entanto, Tefé não tem um porto, mas apenas uma balsa-porto privada e flutuantes de madeira como instalações portuárias rudimentares que constituem um entreposto fluvial.

10 Todos os 62 municípios do estado do Amazonas sofrem interrupções e racionamento de energia elétrica; por isso, o gerador de energia é fundamental na região (Queiroz, 2012).

11 Entrevista concedida por Raifran Rocha da Silva, tripulante da lancha Puma, em Coari, em 26 de dezembro de 2016. 
Sendo assim, os fixos especializados ao transporte fluvial no Solimões atendem de maneira restrita e limitada as operações de barcos modernos como as lanchas Ajato, que devem sua operacionalidade aos Pontões, flutuantes e barcos detentores de equipamentos antigos e técnicas envelhecidas, mas úteis para a fluidez da circulação regional nestes espaços distantes (Figura 6).

\section{Figura 6 - Um dos pontões do lago de Tefé (à esquerda) e o barco de ma- deira que abastece as lanchas em Santo Antônio do Içá (à direita) no Alto Solimões}

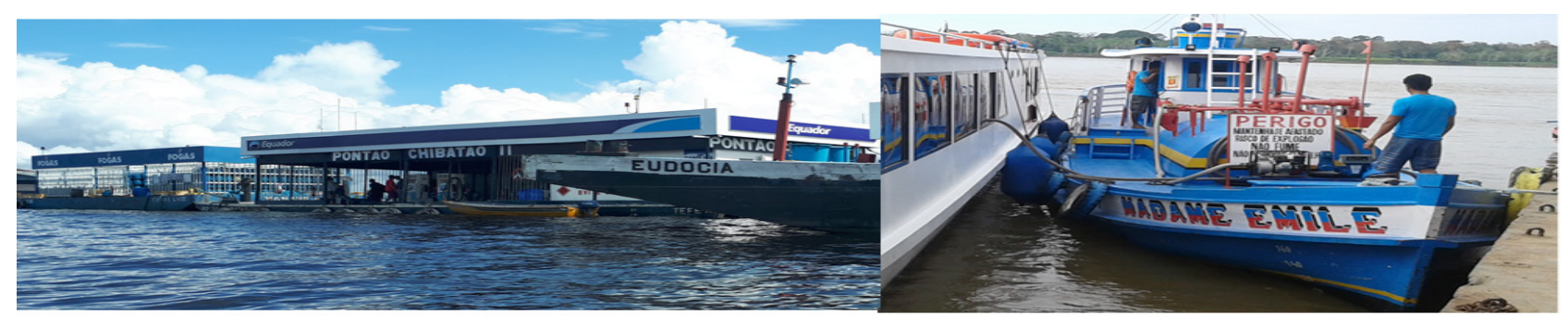

fonte: Acervo do autor, 2019.

Por conseguinte, reflete-se nos guichês e nos representantes de vendas que providenciam as passagens das lanchas Ajato nos municípios inseridos nas respectivas rotas no interior do Amazonas. Nesses lugares, os representantes adquirem $5 \%$ do valor do trecho vendido. A restrita configuração territorial (Santos, 2009[1996]) das cidades do Solimões também restringe os "canais eletrônicos financeiros" I2 (Contel, 2006), o que impossibilita compras com cartão de débito ou crédito ou pela internet, comuns nas transações contemporâneas por meio das tecnologias de informação e comunicação presentes em espaços luminosos. Assim, embora se modernizem as embarcações de transporte de passageiros, não se modernizam os fixos, as estruturas ou as técnicas que deveriam subsidiá-las.

\section{Considerações finais}

A discussão do transporte fluvial de passageiros no rio Solimões por intermédio do papel das lanchas Ajato permitiu conhecer as limitações e os desafios institucionais, infraestruturais e administrativos desse segmento fundamental da circulação regional.

Verificou-se que as lanchas Ajato no Solimões representam objetos do transporte fluvial provenientes de uma especialização do lugar - uma adaptação das embarcações para melhor navegar nos rios amazônicos pela alta potência dos motores e pelo calado menor.

Essas lanchas atendem a todos os municípios do Solimões em sua rota principal, Manaus-Tabatinga-Manaus, ao contrário das embarcações tradicionais, pois os N/M que partem de Tabatinga, no Alto Solimões, descendo até Manaus, não atendem cidades do Médio Solimões como Tefé e Coari; e os recreios que partem de Tefé, no Médio Solimões, para Manaus não contemplam o Alto Solimões. Em função, disso as lanchas Ajato promovem uma integração territorial significativa, além de atender comunidades e lugarejos no Solimões que embarcações de outros segmentos não atendem.

12 Por exemplo, expressos ou caixas eletrônicos, pontos de recebimento de cartõs de crédito e débito, redes de internet banking, centrais de atendimento telefônico etc. (Contel, 2006, p. 253). 
Validou-se a ideia de que as lanchas Ajato modernizaram os fluxos do transporte fluvial no Solimões acelerando a circulação regional e diminuindo a duração das viagens, assim como concorreram para modernizar os fixos a partir da instalação de infraestruturas contemporâneas em seus terminais, como o Terminal do Ajato de Tefé, único da empresa no Solimões, que usa técnicas e equipamentos modernos em lugares carentes de fixos especializados, ganhando expressão por sua contribuição econômica e social. Isso concorre para intensificar a produtividade espacial de Tefé, nó de rede regional.

Os fluxos e a circulação do transporte fluvial favorecem a manutenção e mesmo a atração de novos armadores e empresas para esse mercado, embora o baixo poder aquisitivo da população do interior do Amazonas, tanto dos passageiros quanto da iniciativa privada local, limite a demanda, as iniciativas e os investimentos.

Gerir objetos modernos longe do centro difusor de fluxos no Amazonas, Manaus, não é simples, mas a tradição dentrítica da população que depende do rio para se locomover providencia as perspectivas da navegação no Solimões, perpetuando também seu respeito aos limites e obstáculos do transporte fluvial nessa porção do maior rio do mundo.

\section{Referências}

ANTAQ. AGÊNCIA NACIONAL DE TRANSPORTE AQUAVIÁRIOS. Pesquisa de satisfação dos usuários do serviço de transporte longitudinal de passageiros e misto (passageiros e cargas) na navegação interior da região amazônica. Brasilia: Antaq, 2015.

ANTAQ. AGÊNCIA NACIONAL DE TRANSPORTE AQUAVIÁRIOS. Caracterização da oferta e demanda do transporte fluvial de passageiros na região na região amazônica. Brasilia: Antaq, 2013.

ARROYO, M.; CRUZ, R. C. A. (Org.). Território e circulação: a dinâmica contraditória da globalização. São Paulo: Annablume, 2015.

BALAU, J. A. C. et al. Análise do transporte fluvial de passageiros nos altos rios da Amazônia. São Paulo: Dinav/IPT, 1978.

BATES, H. W. Uma naturalista no rio Amazonas. Trad. Regina Régis Junqueira. Belo Horizonte/São Paulo: Itatiaia/Edusp, 1979[1876].

BRASIL. Ministério da Infraestrutura. Disponível em: http://www.transportes.gov.br. Acesso em: 3 jun. 2016.

CATAIA, M. A. Território nacional e fronteiras internas: a fragmentação do território brasileiro. Tese (Doutorado em Geografia Humana) - Faculdade de Filosofia, Letras e Ciências Humanas da Universidade de São Paulo, São Paulo, 2001.

CNT. CONFEDERAÇÃO NACIONAL DOS TRANSPORTES. Pesquisa CNT da navegação interior 2013. Brasilia: CNT, 2013. 
CONTEL, F. B. Território e finanças: técnicas, normas e topologias bancárias no Brasil. Tese (Doutorado em Geografia Humana) - Faculdade de Filosofia, Letras e Ciências Humanas, Universidade de São Paulo, São Paulo, 2006.

COSTA, W. M. Ordenamento territorial e Amazônia: vinte anos de experiência de zoneamento ecológico e econômico. In: BATISTELLA, M.; MORAN, E. F; ALVES, D. S. (Org.). Amazônia: natureza e sociedade em transformação. São Paulo: Edusp, 2008.

DAMIANI, A. L. Cidades médias e pequenas no processo de globalização: apontamentos bibliográficos. In: LEMOS, A. I. G.; ARROYO, M. M.; SILVEIRA, M. L. (Org.). América Latina: cidade, campo e turismo. Buenos Aires/São Paulo: Clacso/ USP, 2006. p. 135-147.

FERREIRA, M. A. C. Transporte fluvial por embarcações mistas no Amazonas: uma análise do trecho Manaus - Coari e Manaus-Parintins. Tese (Doutorado em Ciências do Ambiente e Sustentabilidade na Amazônia) - Universidade Federal do Amazonas, Manaus, 2016.

HAESBAERT, R. Regional-global: dilemas da região e da regionalização na geografia contemporânea. Rio de Janeiro: Bertrand Brasil, 2010.

HUERTAS, D. M. Da fachada atlântica ao âmago da hiléia: integração nacional e fluidez territorial no processo de expansão da fronteira agrícola. Dissertação (Mestrado em Geografia Humana) - Faculdade de Filosofia, Letras e Ciências Humanas da Universidade de São Paulo, São Paulo, 2007.

IBGE. INSTITUTO BRASILEIRO DE GEOGRAFIA E ESTATÍ́STICA. Atlas do Censo 2010. Coordenação de Geografia. Rio de Janeiro: IBGE, 2013.

MACHADO, P. C. Segurança da navegação em hidrovias: fator fundamental para o desenvolvimento da região Amazônica. Monografia (Graduação em Altos Estudos de Política e Estratégia) - Departamento de Estudos da Escola Superior de Guerra, Rio de Janeiro, 2014.

MOORE, W. E. The impact of industrialization. Englewood Cliffs, NJ: Prentice Hall, 1965.

NOGUEIRA, A. R. B. Geografia das representações. Boletim Amazonense de Geografia, Manaus: AGB, v. 2, p. 93-108, 1995.

NOGUEIRA, R. J. B. Caminhos que marcham: o transporte fluvial na Amazônia. Terra das Águas, Brasilia: UnB, v. 1, n. 2, p. 70-83, 1999.

NOGUEIRA, R. J. B. Amazonas: um estado ribeirinho - estudo sobre o transporte fluvial de cargas e passageiros. Dissertação (Mestrado em Geografia Humana) - Faculdade de Filosofia, Letras e Ciências Humanas, Universidade de São Paulo, São Paulo, 1994.

PEREIRA, V. B. Transportes: história, crises e caminhos. Rio de Janeiro: Civilização Brasileira, 2014.

QUEIROZ, K. O. Centralidade periférica e integração relativizada: uma leitura de Tefé no Amazonas. Tese (Doutorado em Geografia Humana) - Faculdade de Filosofia, Letras e Ciências Humanas, Universidade de São Paulo, São Paulo, 2015. 
QUEIROZ, K. O. Entre motores e velas: os racionamentos e interrupções de energia elétrica no Amazonas. Curitiba: CRV, 2012.

SANTOS, M. A natureza do espaço: técnica e tempo, razão e emoção. 4a ed. São Paulo: Edusp, 2009[1996].

SANTOS, M. O espaço dividido: os dois circuitos da economia urbana dos países subdesenvolvidos. São Paulo: Edusp, 2008[1979].

SANTOS, M. O modo de produção técnico-científico e diferenciação espacial. Território, v. IV, n. 6, p. 5-20, jan./jun. 1999.

SANTOS, M. Por uma economia política da cidade: o caso de São Paulo. São Paulo: Hucitec/Educ, 1994.

SILVEIRA, M. L. Um país, uma região: fim de século e modernidades na Argentina. São Paulo: Fapesp/Laboplan-USP, 1999.

SILVEIRA, M. R. Falta de demanda e deficiência do sistema produtivo brasileiro: contribuições dos eixos de desenvolvimento e dos arranjos produtivos locais. In: SPOSITO, E. S.; SPOSITO, M. E. B.; SOBARZO, O. (Org.). Cidades médias: produção do espaço. São Paulo: Expressão Popular, 2006. p. 103-122.

SINDARMA. SINDICATO DE EMPRESAS DE NAVEGAÇÃO FLUVIAL DO ESTADO DO AMAZONAS. Disponível em: www.sindarma.org.br/transporte_ver/detalhe/passageiros. Acesso em: 15 dez. 2016. 